\title{
Family Quality of Life Following Early Identification of Deafness
}

\author{
Carla W. Jackson \\ Florida State University, Tallahassee \\ Jane R. Wegner \\ Ann P. Turnbull \\ University of Kansas, Kansas City
}

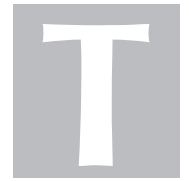

he importance of a family's well-being in the lives and development of young children is widely acknowledged (Allen \& Petr, 1996; Bailey \& Bruder, 2005; Bodner-Johnson, 1986; Bruder, 2000; Calderon, Bargones, \& Sidman, 1998; Dunst, 2002; Guralnick, 1997; Turnbull \& Turnbull, 2001). Part $C$ of the Individuals With Disabilities Education Act (IDEA) Amendments of 1997 requires educators and related service providers to enhance the capacity of families to meet the needs of infants and toddlers. Recognizing the centrality of the family in the life

ABSTRACT: Purpose: Family members' perceptions of their quality of life were examined following early identification of deafness in children.

Method: A questionnaire was used to solicit ratings of satisfaction from the family members of 207 children who were deaf and younger than 6 years of age.

Results: Results indicated that families were generally satisfied with the areas of family life surveyed. Descriptive analysis suggested lower satisfaction ratings in the area of emotional wellbeing. Families also reported that their child's deafness had the largest impact on their emotional well-being. Family members of children using oral communication with a cochlear implant reported higher satisfaction with their child's speech production and perception outcomes than family members of children using hearing aids alone.

Implications: We recommend that service providers and early hearing detection and intervention program coordinators consider additional supports for family well-being following the early identification of deafness in children.

KEY WORDS: deafness, family quality of life, early intervention, emotional support, cochlear implants of the child, clinicians are urged to support family strengths and needs in order to enhance the well-being of the child within the context of the family (Bailey \& Bruder, 2005; Bailey et al., 1998; Bruder, 2000).

The resiliency model of family stress, adjustment, and adaptation provides a conceptual framework for understanding the dynamic relationship between family well-being, stressors, and family resources (McCubbin \& McCubbin, 1993; McCubbin \& Patterson, 1983). This resiliency model is based on the earlier work of Reuben Hill $(1949,1958)$. This conceptual model emphasizes the importance of building the family's capacity to adapt positively to change and/or stress. The well-being of the family system is viewed as a complex interaction of demands, resilience resources, and the family's ability to adapt and problem solve. Based on this model, the health of the family system is a balancing act between stressors and the family's capacity to handle stress. The potential impact of deafness on the family system can be understood given the delicate balance between the demands placed on the family and the resources that mediate stressors. Families' resistance to stressors and their ability to positively adapt to the demands associated with childhood deafness may be influenced by the capacity of the family system, including the family's interpersonal, social, and economic resources.

Considering this model, families may vary in their adaptation following the identification of deafness in one or more of their children. Families with adequate resources may show resilience and adaptation to stressors; other family systems may be vulnerable due to a depletion of resistance resources. Given the importance of the health of the family system, resources that contribute to a family's quality of life may warrant further attention during assessment and early intervention.

Although the literature includes varied definitions of quality of life (Cummins, 1997; Hughes \& Hwang, 1996), key characteristics identified in conceptualizing and measuring the quality of life of individuals include (a) general feelings of well-being, (b) feelings of positive social involvement, and (c) opportunities to achieve personal 
potential (Turnbull, Turnbull, Wehmeyer, \& Park, 2003). The concept of family quality of life is used to capture the overall degree to which the family members' needs are met, the extent to which family members enjoy their time together, and the extent to which they are able to do things that are important to them (Poston et al., 2003). A core aspect in conceptualizing family quality of life involves consideration of the complex, interrelated aspects or domains of family life across interconnected members of the family (Brown, Davey, Shearer, \& Kyrkou, 2004; Poston et al., 2003). Conceptualizations of quality of life were later extended to include outcomes for programs working with families of children with disabilities (Turnbull et al., 2003). Among the valued family outcomes were that families (a) are satisfied with their life situations, services, and supports; (b) are well informed and choose goals and services; and (c) experience continuity, spend time in inclusive environments, and remain connected with natural supports.

A potentially widespread impact of deafness on family quality of life has been reported in reviews of the literature (Jackson \& Turnbull, 2004; Moores, Jatho, \& Dunn, 2001). Jackson and Turnbull (2004) synthesized the literature on the effects of deafness across multiple domains or areas of family quality of life, including emotional well-being, family interaction, parenting, physical well-being, and supports for special needs. Historically, the available literature highlights the potential impacts of deafness across various aspects of family life, including parental stress (Burger et al., 2005; Hintermair, 2000), decision making (Calderon \& Greenberg, 1999; Meadow-

Orlans, Mertens, Sass-Lehrer, \& Scott-Olson, 1997), family interactions (Bodner-Johnson, 1991; Evans, 1995; Freeman, Dieterich, \& Rak, 2002; Kashyap, 1986), and social networks (Gregory, Bishop, \& Shelton, 1995). Quittner, Steck, and Rouiller (1991) examined parental stress and adjustment, comparing the stress levels of 96 mothers of children with hearing loss to those of a control group of mothers of children with typical hearing. Mothers of the children who were deaf reported significantly higher stress levels than mothers of the children with typical hearing. Qualitative studies have also described the experiences of families, including challenges involved in reacting to the diagnosis of hearing loss, decision making, engaging in family interactions, participating in recreation, ensuring safety, and overcoming system barriers (Freeman et al., 2002; Jackson, Traub, \& Turnbull, 2008).

A limited number of studies are beginning to examine the impact of deafness on child and family well-being given the potential impact of universal newborn hearing screening, early identification, information gathering, and decision making. Researchers have speculated that earlier identification and intervention of deafness will result in better bonding and family adaptation. Other researchers have predicted a greater need for early emotional support as parents are faced with the challenges of adjustment at a delicate time, shortly after their child's birth. Today, resources and supports that promote positive adaptation for families after early identification are not well understood.

Recent qualitative studies (Jackson et al., 2008; Young \& Tattersall, 2007) support the notion that families differ in their reactions and adaptation following early identification of deafness in a child. Young and Tattersall (2007) interviewed 45 parents of 27 infants in a qualitative study shortly after universal newborn hearing screening. The authors examined the parents' perceptions of the impact of the screening process and its consequences for intervention. The majority of parents studied had positive perceptions of the early identification process. Parents reported emotional reactions of shock and grief; however, grief was partially offset by the early intervention. Young and
Tattersall suggested that the parents' distress was moderated through opportunities for earlier intervention and the chance to adapt to their child's needs early in life. For other parents, early identification was a source of distress as their initial joy of having a new baby was overshadowed by the beginning of a grieving process. Other parents reportedly focused on the promise of "normalization" through early intervention and reported heightened stress with a sense of urgency to act quickly in order to maximize the potential benefits of early identification.

Several studies have reported no significant differences in stress levels between families of children with typical hearing and those of children who were deaf. Meadow-Orlans, Spencer, and Koester (2004) examined the stress levels of 40 highly educated parents in urban settings and found no significant differences in stress levels between parents of children 9 and 15 months old with typical hearing and parents of children in early intervention who were deaf. Similarly, Weisel, Most, and Michael (2007) used the Parenting Stress Index (Abidin, 1990) to survey the mothers of 64 deaf children in Israel between 9 months and 14 years of age. The authors compared the stress of the parents of 10 children at pre-implantation with that of the parents of 31 children who had been implanted for up to 3 years and 23 who had been implanted for 3-9 years. The results indicated normal stress levels for all three groups of parents, with no significant differences in family stress between groups.

Other studies have reported heightened challenges and stress in adapting to deafness immediately after identification, but not consistently across ages or groups differing in their use of sensory devices. Burger et al. (2005) studied the stress levels and perceived quality of life of 91 parents of children in Germany who were deaf. All families reported heightened stress levels and diminished quality of life shortly after diagnosis (6-8 weeks) based on their responses on a stress survey and the Everyday Life Questionnaire (Bullinger, Kirchberger, \& Steinbuchel, 1993). However, parents of children with cochlear implants reported reduced stress and improved quality of life after implantation (approximately 7 months after initial survey), whereas parents of children with hearing aids continued to report heightened stress $(t=2.61, p=.009)$ and diminished quality of life $(t=4.55, p=.001) 6-7$ months after hearing aid fitting. Most and Zaidman-Zait (2003) surveyed 35 mothers of children who were deaf and used cochlear implants or were candidates for implants. Of the mothers who participated in this qualitative study, $36.4 \%$ indicated that they lacked emotional support.

The relationship between stress, social support, and life satisfaction after the identification of deafness in a child was further examined by Lederberg and Golbach (2002). Their study investigated the impact of deafness on mothers' stress, social networks, and satisfaction with social support over a 2 -year period. Mothers of 23 children who were deaf and mothers of 23 children with typical hearing were surveyed when their children were aged 22 months, 3 years, and 4 years. When their child was 22 months old, mothers of children who were deaf demonstrated significantly greater stress than mothers of children with typical hearing. However, significant differences in stress levels between the two groups were not found when the children were 3 and 4 years old. The authors reported a relationship between social support, parenting stress, and life satisfaction. Parents who reported heightened stress levels reported less satisfaction with social supports $(\beta=-.76)$. Furthermore, parents with less satisfaction with social support also indicated lower ratings of life satisfaction $(\beta=.34)$. Whereas the majority of mothers were satisfied with social support, $10 \%-33 \%$ of the mothers expressed dissatisfaction with the support of partners, friends, and professionals. 
Consensus on the effects of deafness on family quality of life has not been established. Mixed findings have been reported regarding parental stress and adaptation, family interaction, social networks, and access to supports and resources. Some studies have reported that families continue to experience heightened stress and inadequate supports following the identification of deafness in their child; other findings reflect positive adaptation and general well-being after early identification and intervention.

Given the importance of family well-being to the development of young children, a better understanding of the impact of deafness on family life and family members' perceptions of family quality of life is needed. Additional examination of the impact of deafness on families is needed to identify critical program supports and to assist clinicians in supporting overall family quality of life in an effort to enhance both child and family outcomes following the early identification of deafness. The purpose of this study was to investigate families' perceptions of their quality of life following the early identification of deafness in their child in order to identify key areas of desired family support and provide recommendations for program enhancement. This inquiry addressed the following questions:

- What trends in family quality of life exist for families in which a child is identified as deaf at a young age?

- How satisfied are families with areas of family life?

- What areas of family life do families perceive to be affected by their child's deafness?

- What additional supports do families of children who are deaf desire?

\section{METHOD}

\section{Procedures}

Due to the low-incidence nature of this population, we mailed surveys to facilitate distribution to a large number of potential participants located over a wide geographic area. Wide distribution was desired in an effort to include diverse voices and experiences, reflecting varied communication methods, types of sensory device, and services. The survey included quantitative questions as well as one open-ended qualitative question in an effort to solicit feedback that may not have been captured by the scaled questions.

In order to obtain a cross-section of gender, race, and socioeconomic backgrounds, we sent invitations to a variety of agencies and service providers representing diverse approaches, types of agencies, and locations. We recruited participants from public and private agencies serving children who are deaf across the United States. Cooperating agencies differed by state and included state schools for the deaf, private oral schools, private clinics, and Part C programs. In several states, the early hearing detection and intervention state coordinator or a family resource specialist served as a liaison in disseminating invitations to agencies serving young children who were deaf or hard of hearing and did not have identified disabilities other than hearing loss.

To solicit the cooperation of agencies, we mailed an informational letter describing the purpose of the study to agency directors, family resource specialists, and related educators and personnel. We asked them to distribute the enclosed invitations to eligible family members. Upon receipt of the completed invitation card, we mailed a packet containing a consent and informational letter and questionnaire to the families, along with $\$ 5.00$ as a token of appreciation. A monetary incentive of $\$ 5.00$ was included based on research indicating a 19\% improved response rate with a token financial incentive (Church, 1993; Dillman, 2000). We mailed a follow-up letter to those families who did not return the completed survey after 1 month.

\section{Instrument}

We used a scale of family quality of life, developed at the University of Kansas Beach Center on Disability (Beach Center Family Quality of Life Scale, FQoL; Poston et al., 2003), to solicit family members' perceptions of their family's well-being. The FQoL scale was validated through three field tests. Initially, a national survey was conducted including 1,037 family members of individuals with disabilities (Park et al., 2003). Families were asked to identify and rate areas they felt were important to the family's quality of life. Subsequently, some items were dropped due to low loading, ambiguous wording, or redundancy. A second field test was conducted to test the 40 items that emerged from the initial pilot study. This time, data were collected from 209 family members, mostly mothers, on the importance of the identified family quality of life indicators. Alphas ranged from .86 to .91 for ratings of importance. A third field test of 280 families with children in early childhood services was conducted (Summers et al., 2005) with similar results to the second field test. After thorough analysis of the factor structure, the final domains reflected in the current scale included health and financial well-being, emotional well-being, family interaction, parenting, and support for the individual with a disability. Examination of test-retest reliability and convergent validity resulted in satisfactory levels.

For the purpose of this study, we modified the questionnaire slightly, omitting a few questions related to adults with disabilities that were not applicable to this age group (e.g., job satisfaction). The introduction to the questionnaire provided a description of family well-being, general instructions, and a sample item. The nature of the questions in the complete questionaire focused on (a) the family's satisfaction with family life, (b) the impact of deafness on family life, (d) child outcomes, and (e) desired family supports.

Satisfaction with family life. Using the FQoL scale, we asked family members to indicate their degree of satisfaction with various items using a 5-point scale including degree headings ranging from very dissatisfied to very satisfied. The FQoL scale attempts to capture the overall degree to which family members' needs are met, the extent to which they enjoy their time together, and the extent to which they are able to do things that are important to them (Poston et al., 2003). The items are grouped by five domains: health and financial well-being, emotional well-being, family interaction, parenting, and support for the child who is deaf. Each of the five domains includes $4-6$ individual items, for a total of 26 items. The health and financial well-being domain asks about the family's access to medical and dental care, transportation, taking care of expenses, and feeling safe. The emotional well-being domain asks participants to rate their satisfaction with support to relieve stress, having friends who provide support, having time to pursue individual interests, and having support to take care of special needs. The family interaction domain includes items related to talking openly with each other, showing love, and enjoying time together. The parenting domain includes items such as helping children with learning activities, teaching children to get along and make good decisions, and taking care of the 
needs of every child. Finally, the support for special needs section asks families to rate the support they received to make progess and to have friends, as well as the quality of their relationships with service providers.

Impact of deafness on family life. For the purposes of this study, an additional area of measurement was added to the FQoL scale. We asked family members to rate the impact of deafness on each item in the FQoL scale using a 5-point scale with identified descriptors ranging from no impact to moderate impact to large impact.

Child outcomes. We asked family members to identify the impact of deafness related to child outcomes, as well as their satisfaction with their child's progress. Specifically, we asked participants about the impact of deafness and their satisfaction with their child's speech production skills, overall language skills, and speech perception or listening skills.

Family supports. We included one open-ended question on the survey to solicit comments and experiences. In an effort to solicit aspects that may be important to families or unique to this population that were not anticipated in the closed questions of the scales and indicators, we asked participants to identify family supports they desired during early intervention.

\section{Participants}

The study included the families of 207 children ages 0 through 6 years who were deaf or hard of hearing. Participants were receiving services from agencies in 42 states. Of the 263 requested surveys, 211 were completed and returned, reflecting an $80 \%$ response rate. Of the 211 returned surveys, 4 were later eliminated from the data pool due to the child's age at the time of the survey, leaving 207 participants in the data pool.

The sample is described in relation to the (a) demographics of the families, (b) child characteristics, and (c) services received. Respondents varied by region, race, income, family role, education level, marital status, community size, and other demographic characteristics. Children varied by communication method, type of sensory device used, age of identification, age at time of survey, degree of hearing loss, and type and frequency of services received.

Demographic characteristics of families. The majority of respondents were mothers who reported being the primary caregiver of the child who was deaf. Respondents were primarily Caucasian (172, 83\%); small numbers reported being Hispanic (13, 6\%), Asian (8, 4\%), African American (7, 3\%), American Indian (2, 1\%), and other $(2,1 \%)$. Three participants did not respond to this question. The 207 families were distributed across 42 states in differing geographic regions of the United States, with a large group from the Midwest. Reported household income ranged from $\$ 14,000$ to $>\$ 75,000$, with a median household income of $\$ 43,318$. Approximately one third of the respondents reported an income $<\$ 35,000$ $(59,28 \%)$, more than one third reported an income between $\$ 35,000$ and $\$ 75,000(82,39 \%)$, and approximately one third reported an income $>\$ 75,000(56,29 \%)$. Ten participants did not respond to this question. The majority of participants $(97 \%)$ reported supporting 2 adults on this income and $1-3$ children (88\%). The majority had participated in postsecondary education. Table 1 includes a complete description of the demographics of the respondents.

Characteristics of the children. All of the children in this study had been identified as having a hearing loss in the absence of any other significant disability. The children ranged in age from 2 months to 72 months, with no more than $10 \%$ of the sample at any particular
Table 1. Demographics of family respondents $(N=207)$.

\begin{tabular}{|c|c|c|}
\hline Variable & Number & Percentage of sample \\
\hline \multicolumn{3}{|l|}{ Family role } \\
\hline Mother & 186 & 90 \\
\hline Father & 16 & 8 \\
\hline Grandmother & 3 & 1 \\
\hline Other & 2 & $<1$ \\
\hline \multicolumn{3}{|l|}{ Racial distribution } \\
\hline Caucasian & 172 & 83 \\
\hline Hispanic & 13 & 6 \\
\hline Asian & 8 & 4 \\
\hline African American & 7 & 3 \\
\hline American Indian & 2 & 1 \\
\hline Other & 2 & 1 \\
\hline Did not respond & 3 & 2 \\
\hline \multicolumn{3}{|l|}{ Geographic region $^{\mathrm{a}}$} \\
\hline West & 55 & 26 \\
\hline Midwest & 64 & 31 \\
\hline South & 54 & 26 \\
\hline East & 34 & 16 \\
\hline \multicolumn{3}{|l|}{ Household income } \\
\hline$<\$ 35,000$ & 59 & 28 \\
\hline$\$ 35,000-\$ 75,000$ & 82 & 39 \\
\hline$>\$ 75,000$ & 56 & 29 \\
\hline Did not respond & 10 & 5 \\
\hline \multicolumn{3}{|l|}{ Education } \\
\hline High school diploma & 8 & 4 \\
\hline GED & 19 & 9 \\
\hline College but no degree & 46 & 22 \\
\hline Associates degree & 19 & 9 \\
\hline Bachelor's degree & 69 & 33 \\
\hline Graduate degree & 46 & 22 \\
\hline \multicolumn{3}{|l|}{ Marital status } \\
\hline Married & 176 & 85 \\
\hline Never married & 15 & 7 \\
\hline Divorced & 9 & 4 \\
\hline Separated & 4 & 2 \\
\hline Widowed & 3 & 1 \\
\hline \multicolumn{3}{|c|}{ Number of family members who are deaf ${ }^{\text {b }}$} \\
\hline Child only & 146 & 71 \\
\hline Two members & 25 & 12 \\
\hline Three members & 7 & 3 \\
\hline Four members & 7 & 3 \\
\hline \multicolumn{3}{|l|}{ Community size ${ }^{\mathrm{b}}$} \\
\hline Large city $(>200,000)$ & 82 & 40 \\
\hline Urbanized area & 47 & 23 \\
\hline Town or small city & 59 & 28 \\
\hline Rural area & 16 & 8 \\
\hline
\end{tabular}

Note. Percentages of total respondents have been rounded to the nearest whole. Percentages do not equal $100 \%$ due to rounding and incomplete responses.

${ }^{a}$ Divisions of geographic regions are based on those of the U.S. Census Bureau.

${ }^{\mathrm{b}}$ Remaining percentages for items represent the absence of a numeric response or a skipped item by participants.

age. The mean age of the children was 44 months, with a standard deviation of 16.58 months. The age of identification ranged from birth $(32 \%)$ to 42 months $(<1 \%)$, with a median of 5.5 months. The majority of the children had a severe or profound degree of hearing loss (76\%), with only $3 \%$ reporting a mild degree of hearing loss and $16 \%$ reporting a moderate degree. The sample contained roughly equal 
representation of sensory device type, as approximately half of the children used hearing aids alone (95) and approximately half used cochlear implants (103). A few families reported that their child was not using any form of sensory device at the time of the survey (refer to Table 2).

Children also varied in their preferred communication method. Respondents identified one of three primary methods of communication: sign language $(n=28,14 \%)$, oral speech $(n=119,58 \%)$, and total communication $(n=56,27 \%)$, which is a combination of speech and sign. The portion of children using primarily oral speech was slightly higher $(63 \%)$ for the subgroup of children who had a cochlear implant; only $6 \%$ of the children with an implant reported sign language alone as their primary method of communication. In contrast, of the children who did not wear a sensory device, 4 out of 5 respondents reported sign as their child's primary method, and 1 reported total communication (refer to Table 2).

Services received. The majority of children in the survey received services from at least three different types of providers: speechlanguage pathologist (SLP; $n=165)$, teacher of the deaf $(n=129)$, and audiologist $(n=148)$. For services from an audiologist, 148 had regular services visits, and the remaining children received services from an audiologist on an "as needed" basis. Other professionals providing services to the children included early childhood special educator $(n=49)$, auditory verbal therapist $(n=77)$, and deaf mentor $(n=18)$.

The number of times services were provided per week ranged from a fraction (once every 3 months or monthly) to five times a week, but the majority of services were provided two or three times per week. The highest mean frequency was reported with teachers of the deaf, who served children an average of 3.66 times per week $(S D=1.75)$. This may be related to the age and educational level of the children, as many preschool-age children attend 4-day-a-week preschools. The second highest mean frequency was reported with early childhood special education providers, who served children an average of 2.89 times per week $(S D=1.9)$, also perhaps due to preschool enrollment. Finally, SLPs served children an average of 2.61 times per week $(S D=1.6)$, and auditory verbal therapists provided services an average of 2.1 times per week $(S D=1.7)$.

The total number of sessions per week was similar across all groups of children. The average number of sessions for children using one of each sensory device, both a cochlear implant and a hearing aid, was 10.57. Children with a cochlear implant received an average of 9.64 sessions per week; children with hearing aids received

Table 2. Primary communication method of the children.

Type of communication

Total

Participant Sign language Oralspeech communication

All

Cochlear implant users

Hearing aid users

No sensory device

$28(13.5 \%)$
6
16
4

119

an average of 9.16 sessions per week. Children using sign as their primary communication method received an average of 11.5 sessions per week, total communication users received an average of 9.43 sessions per week, and oral communicators received an average of 9.16 sessions per week.

Family supports. Respondents noted that the majority of services were child oriented, with fewer family supports provided. The most commonly reported family support was parent education or informational support $(n=97,47 \%)$. Roughly one third of the respondents reported participating in a parent support group $(n=73,35 \%)$. Fiftyeight participants reported receiving financial assistance (28\%), 32 reported receiving transportation support (15.5\%), and only 7 reported receiving respite care $(3.4 \%)$. Seventeen respondents reported receiving other types of family support $(8 \%)$.

\section{RESULTS}

\section{Satisfaction With Areas of Family Life}

Table 3 presents the mean ratings of satisfaction for indicators of family well-being across all domains of the FQoL scale. Descriptive analysis revealed that the lowest satisfaction means were observed for the following items: having time to pursue interests (3.34), having support to relieve stress (3.35), getting services from local agencies (3.83), inclusion in the community (3.88), and having a way to take care of expenses (3.95). All other means were $\geq 4.0$, indicating that parents reported being mostly satisfied with those areas of life.

A mean score for each domain of family life was computed by averaging the individual ratings for items on the questionnaire. The number of participants ranged from 205 to 207, due to the fact that a mean score was only computed for participants who completed ratings for at least three items in the domain. The mean for emotional well-being was the lowest, at $3.65(S D=.94)$. All other domain means were $>4.0$ : The mean for health and financial well-being was $4.38(S D=.65)$, for family interaction was $4.27(S D=.76)$, for parenting was $4.33(S D=.79)$, and for support was $4.22(S D=.79)$.

We conducted a multivariate analysis of variance (MANOVA) to identify potential differences in participants' satisfaction with domains of family life when compared to child's communication method, type of sensory device, and age and parent's level of income. Income yielded a significant effect on the satisfaction ratings for physical and financial well-being: $\Lambda=.834, F(10,380)=3.60$, $p=.000, \eta^{2}=.087$. As expected, low-income families reported lower satisfaction ratings with items that related to physical and financial well-being. There were no other significant differences in satisfaction ratings for any of the five domains (health and financial well-being, emotional well-being, family interaction, parenting, or support for special needs) when tested at the .05 level. The obtained main effect sizes were small, accounting for between $1 \%$ and $4 \%$ of the total variance in satisfaction ratings.

\section{Impact of Deafness on Areas of Family Life}

Table 4 indicates the mean ratings of the impact on deafness for each item across all domains. Higher numbers indicate perceptions of a larger impact of deafness than lower numbers. Based on descriptive analysis, items demonstrating the largest means for impact of deafness were observed for the following items: taking care of the special needs of all family members (3.10), having support to relieve 
Table 3. Mean satisfaction rating: Indicators of family well-being.

\begin{tabular}{llrr}
\hline \multicolumn{1}{c}{ Survey item } & N & M & SD \\
& & & \\
& & & \\
& 206 & 4.58 & .77 \\
Has adequate medical care & 204 & 4.26 & 1.10 \\
Has adequate dental care & 205 & 4.06 & 1.08 \\
Has support to take care of the needs of all members & 205 & 3.35 & 1.24 \\
Has support to relieve stress & 205 & 4.00 & 1.08 \\
Has friends who provide support & 205 & 3.34 & 1.31 \\
Has time to pursue individual interests & 205 & 4.50 & .86 \\
Has transportation & 204 & 3.95 & 1.05 \\
Has a way to take care of expenses & 206 & 4.62 & .79 \\
Feels safe at home, work, school and neighborhood & 207 & 4.60 & .80 \\
Enjoys spending time together & 207 & 4.09 & .95 \\
Handles life's ups and downs & 204 & 4.25 & .95 \\
Supports each other to accomplish goals & 207 & 4.14 & 1.05 \\
Talks openly with each other & 206 & 4.02 & 1.07 \\
Solves problems together & 207 & 4.40 & 1.03 \\
Knows people in children's lives & 207 & 4.41 & .86 \\
Teaches the children how to get along & 207 & 4.36 & .94 \\
Has information needed to make decisions & 205 & 4.39 & .92 \\
Teaches the children to make good decisions & 207 & 4.00 & 1.11 \\
Has time to take care of the individual needs of child. & 206 & 4.38 & .91 \\
Helps children learn to be independent & 206 & 4.35 & 1.09 \\
Has support to make progress at school or child care & 206 & 4.49 & .89 \\
Has support to make progress at home & 207 & 4.19 & 1.01 \\
Has support to make friends & 204 & 3.88 & 1.13 \\
Has support to be included in community activities & 206 & 3.83 & 1.35 \\
Has support to get needed services from local agencies & 206 & 4.53 & .92 \\
Has good relationships with service providers & & & \\
\hline
\end{tabular}

Note. The higher the mean number, the greater the satisfaction: $1=$ very dissatisfied, $3=$ neutral, $5=$ very satisfied. The total number $(N)$ indicates the number of participants who responded to the specific item on the survey. Items with an $N$ of $<207$ reflect the absence of a response or a skipped item by 1 or more participants.

Table 4. Mean ratings of the impact of deafness on items of family life.

\begin{tabular}{|c|c|c|c|}
\hline Survey item & $\mathrm{N}$ & M & $\mathrm{SD}$ \\
\hline Has adequate medical care & 203 & 2.32 & 1.46 \\
\hline Has adequate dental care & 204 & 1.80 & 1.21 \\
\hline Has support to take care of the special needs of all members & 202 & 3.10 & 1.52 \\
\hline Has support to relieve stress & 202 & 3.05 & 1.46 \\
\hline Has friends who provide support & 203 & 2.88 & 1.52 \\
\hline Has time to pursue individual interests & 205 & 3.34 & 1.31 \\
\hline Has transportation & 205 & 1.98 & 1.40 \\
\hline Has a way to take care of expenses & 201 & 2.76 & 1.50 \\
\hline Feels safe at home, work, school, and neighborhood & 205 & 2.00 & 1.42 \\
\hline Enjoys spending time together & 206 & 2.15 & 1.46 \\
\hline Handles life's ups and downs & 205 & 2.78 & 1.42 \\
\hline Supports each other to accomplish goals & 204 & 2.50 & 1.43 \\
\hline Talks openly with each other & 202 & 2.33 & 1.45 \\
\hline Solves problems together & 206 & 2.30 & 1.40 \\
\hline Knows people in children's lives & 205 & 2.76 & 1.58 \\
\hline Teaches the children how to get along & 205 & 2.65 & 1.52 \\
\hline Has information needed to make decisions & 204 & 2.95 & 1.56 \\
\hline Teaches the children to make good decisions & 203 & 2.34 & 1.47 \\
\hline Has time to take care of the individual needs of child & 206 & 3.12 & 1.62 \\
\hline Helps children learn to be independent & 204 & 2.83 & 1.59 \\
\hline
\end{tabular}

Note. The higher the mean number, the greater the perceived impact: $1=$ no impact, $3=$ moderate impact, 5 = large impact. The total number $(N)$ indicates the number of participants who responded to the specific item on the survey. Items with an $N$ of $<207$ reflect the absence of a response or a skipped item by 1 or more participants. 
stress (3.05), having time to pursue interests (3.34), and having time to take care of the individual needs of every child (3.12). Items related to support for special needs were not included in the analysis or description of impact. All other means were $\leq 2.9$, indicating that parents reported less than a moderate impact of deafness on other areas of family life.

We computed a mean score for each of the four domains of family life. The number of participants ranged from 201 to 206, as a domain mean was only computed for participants who completed ratings for at least three items in the domain. The emotional well-being domain demonstrated the largest impact of deafness, with a mean rating of $3.02(S D=1.28)$. Other domains reflected a small to moderate impact of deafness: The mean impact of deafness on parenting was $2.82(S D=1.31)$, the mean impact of deafness on family interaction was $2.36(S D=1.21)$, and the mean impact on health and financial well-being was $2.17(S D=1.06)$.

We conducted a MANOVA to identify potential differences in ratings of impact of deafness for domains of family life when compared to communication method, type of sensory device, level of income, and age. There were no meaningfully significant differences or interactions between groups on communication method, sensory device, level of income, or age for the four domains when tested at the .05 level. The type of sensory device used did not have a significant effect on families' perceptions of the impact of deafness on their physical well-being $\left(p=.990, \eta^{2}=.000\right)$, emotional well-being $\left(p=.142, \eta^{2}=.011\right)$, family interaction $\left(p=.378, \eta^{2}=.004\right)$, or parenting $\left(p=.986, \eta^{2}=.000\right)$. Families who differed in their communication modality did not report significantly different ratings of the impact of deafness on emotional well-being $\left(p=.331, \eta^{2}=.011\right)$, family interaction $\left(p=.286, \eta^{2}=.013\right)$, or parenting $(p=.115$, $\eta^{2}=.022$ ). Communication modality did yield a statistically significant effect on families' perceptions of the impact of deafness on physical and financial well-being $\left(p=.002, \eta^{2}=.064\right.$, with an observed power of .908); however, a follow-up analysis indicated that communication modality groups were not equally distributed by income levels, so this effect was not considered meaningful.

\section{Child Outcomes}

The means for impact of deafness on communication outcomes were all $\geq 4$ (based on a 5-point scale), indicating that the average

Table 5. Mean satisfaction with child outcomes split by sensory device and communication method.

\begin{tabular}{|c|c|c|c|c|c|c|}
\hline \multirow[b]{2}{*}{ Skill } & \multicolumn{3}{|c|}{ Sensory device } & \multicolumn{3}{|c|}{$\begin{array}{l}\text { Communication } \\
\text { method }\end{array}$} \\
\hline & $H A$ & $C I$ & $C I / H A$ & Sign & $T C$ & Oral \\
\hline Speech perception* & 3.84 & 4.06 & $4.71 *$ & 3.53 & 4.03 & $4.42 *$ \\
\hline Clarity of speech* & 3.67 & 3.73 & $4.30 *$ & 2.81 & 3.99 & $4.18^{*}$ \\
\hline Language (signed or spoken) & 4.17 & 4.10 & 4.57 & 3.85 & 4.24 & 4.37 \\
\hline
\end{tabular}

Note . $\mathrm{HA}=$ children using hearing aids, $\mathrm{CI}=$ children using a cochlear implant, $\mathrm{CI} / \mathrm{HA}=$ children using both a cochlear implant and a hearing aid, Sign = sign language is primarily used for communication, $\mathrm{TC}=\mathrm{a}$ combination of sign and speech is used for communication, Oral = communication relies on oral speech without the use of sign language.

*Significant differences observed between groups, $p<.01$. family perceived deafness to have a large impact on their child's communication outcomes. Table 5 provides the mean ratings of parents' satisfaction with their child's progress in speech clarity, language development, and speech perception or listening skills. The data are split by subgroups of sensory device type and communication method.

We conducted a MANOVA to examine the satisfaction with communication outcomes between groups (communication method, sensory device, income, and age). A significant main effect was found for sensory device type and communication method, with a significant interaction of the two. The type of sensory device used yielded a significant effect on parents' satisfaction with their child's communication outcomes: $\Lambda=.894, F(6,278)=2.68, p=.015, \eta^{2}=.055$, with an observed power of .86 , reflecting a moderate effect size. The method of communication yielded a significant effect on parents' satisfaction with their child's communication outcomes: $\Lambda=.872$, $F(6,278)=3.271, p=.004, \eta^{2}=.066$, with an observed power of .93 , reflecting a moderate effect size. There was a significant interaction of sensory device type and communication modality on parents' satisfaction with their child's communication outcomes: $\Lambda=.859$, $F(9,338)=2.43, p=.011, \eta^{2}=.050$, with an observed power of .84 . Other fixed variables (income level and age) did not yield meaningfully significant differences.

Pairwise follow-up tests for significant items examined mean differences between each group separately using Tukey's HSD. Table 5 depicts the means for the individual subgroups. Significant mean differences were found between two sensory device groups (children using hearing aids and children using both a cochlear implant and a hearing aid) for satisfaction with auditory speech perception progress $(p=.004)$, with a mean difference of 1.35 at the $95 \%$ confidence interval (.25 SE). Family members of children using cochlear implants and hearing aids (combined) reported higher satisfaction with children's auditory speech perception progress than did family members of children who used hearing aids alone. A significant mean difference ( $p=.031)$ was also found between type of sensory device used and family satisfaction with children's progress in clarity of speech, with a mean difference of 1.33 at the $95 \%$ confidence interval (.29 SE).

We also used a follow-up Tukey's HSD to examine mean satisfaction differences between groups using different communication methods. Family members of children using primarily oral communication were more satisfied with their child's progress in speech clarity $(p=.00)$ and more satisfied with their child's speech perception skills than were family members of children whose primary communication method was sign language $(p=.00)$. Satisfaction with progress in speech perception was also significantly higher for family members of children using oral communication when compared to families of children using total communication $(p=.01)$.

\section{Qualitative Analysis: Family Experiences and Desired Supports}

We conducted a qualitative analysis on parents' written responses to an open-ended question combined with their written responses on a comment section of the survey. The most frequently occurring themes included positive early intervention experiences and the desire for increased informational support, improved educational programs, increased financial support, additional support for family life, and additional parent support groups. Table 6 contains a complete 
Table 6. Frequency of occurrence of themes in family experiences and desired supports.

\begin{tabular}{|c|c|}
\hline Theme & $\begin{array}{l}\text { Number of } \\
\text { occurrences }\end{array}$ \\
\hline Increased informational support & 29 \\
\hline Oral communication & 7 \\
\hline Signing and/or ASL & 5 \\
\hline All communication options & 4 \\
\hline General training and information & 3 \\
\hline Assistive listening and implants & 5 \\
\hline Educational programs & 3 \\
\hline Deaf community/Deaf culture & 2 \\
\hline Positive early intervention experiences & 23 \\
\hline Improved educational programs & 21 \\
\hline Support for transition & 6 \\
\hline Auditory verbal or oral programs & 5 \\
\hline Strategies for school & 3 \\
\hline Access to programs by location & 2 \\
\hline Improved preschool programs & 2 \\
\hline Deaf mentors and role models & 2 \\
\hline Diagnostic follow-up & 1 \\
\hline Increased financial support & 20 \\
\hline $\begin{array}{l}\text { Accessing insurance benefits or general other sources } \\
\text { for assistive listening devices and implants }\end{array}$ & 11 \\
\hline General financial support & 4 \\
\hline Accessing insurance benefits for services & 3 \\
\hline Financial assistance for interpreters & 1 \\
\hline Financial assistance for respite care & 1 \\
\hline Additional support for family life & 19 \\
\hline Support to relieve stress/guilt & 3 \\
\hline Support for siblings & 3 \\
\hline Knowledge of parenting & 3 \\
\hline Including child in daily life interactions & 3 \\
\hline Time for individual interests & 1 \\
\hline Family and marriage counseling & 2 \\
\hline Respite care & 1 \\
\hline Quality child care with special training & 2 \\
\hline Signing support at home & 1 \\
\hline Additional parent support groups & 14 \\
\hline Service providers with specialized knowledge and training & 10 \\
\hline Auditory verbal training & 2 \\
\hline Specialty qualifications & 4 \\
\hline Auditory training & 1 \\
\hline Knowledge of cochlear implants & 2 \\
\hline Part C & 1 \\
\hline Support for inclusion in community & 8 \\
\hline Education and resources for community personnel & 6 \\
\hline Access to interpreters & 2 \\
\hline Increased therapy desired & 6 \\
\hline Negative experiences & 2 \\
\hline Unable to access option of choice & 1 \\
\hline Lost to follow-up post screening & 1 \\
\hline
\end{tabular}

list of themes and the number of units or occurrences relating to each theme and subgroup.

Access to informational support was the most frequent theme in participants' comments. As indicated in the subtopics in Table 6, the desire for additional informational supports was not specific to any one area or type of desired information but was diversified across a number of desired areas. Parents indicated a desire for additional informational resources on communication modalities, sensory devices, educational programs, and Deaf culture.

Comments about positive early intervention experiences were the second most frequent theme in the written responses of family members. Family members' comments reflected positively on newborn hearing early identification and Part $\mathrm{C}$ early intervention efforts, with comments such as "early intervention $0-3$ is a great start." The largest percentage of comments involved praise for a specific program, approach, or service provider, or the child's general progress. Many of the positive comments were specific to children's progress and outcomes during early intervention. As one parent expressed, "We have recently been released from the private speech therapist because of the progress that our son has made."

Parents also commented about the difficulty of accessing desired educational programs. As one parent stated, "I would like my son to attend the private preschool and be paid for transportation, but I see a battle. I also see a child who is progressing with oral, and as he continues to, I continue to fight my battles. I wish it wasn't so hard." Ten participants indicated a need to access service providers with specialized training. Several families commented about the lack of geographic access to desired programs. Two families wrote that they had relocated to a different state for desired programs. Another family member commented that she regularly drove $2 \frac{1}{2} \mathrm{hr}$ to access desired services.

Increased financial support was another frequently occurring request in families' written responses and comments. Themes around financial support included accessing insurance benefits for assistive listening devices and cochlear implants and services, obtaining general financial support, and funding interpreters and respite care. As one family member stated, "The cost of hearing aids is crazy. Although some places you can get donations or sponsorships, I feel something should be done to push insurance companies to cover hearing aids for all people." Similarly, another family member wrote, "Though we were able to financially support our child as it pertains to his special needs, we think it is deplorable that so many services that our child needs cost so much money."

The written comments also highlighted the desire for additional supports for family life and general family well-being. Families recommended support for parents related to general emotional wellbeing, stress relief, counseling, and time to pursue individual interests. One family member stated, "Marriage and family counseling would be helpful for dealing with issues of grief and guilt and to understand the unrelenting stress having a young deaf child places on a marriage and family." Another parent expressed, "[there needs to be] ... a stress outlet. Mother supports [the] family, but could use support herself sometimes and there is none. Mother has many interests, not easily able to pursue due to time and money restraints, which deafness has a large impact."

Many families provided written comments about the pervasive impact of deafness on family life. One family's comment highlighted the need for increased awareness of the pervasive impact of deafness, stating that "[there needs to be]...more awareness to our needs and that of our children. People know about deafness, but don't understand the impact on our lives. Our lives have changed a lot since our baby was born deaf." Additional comments reflecting the pervasive impact of deafness were related to support for siblings, parenting, family interactions; time for individual interests; family and marriage counseling; respite care; the need for quality child care with special training; as well as signing support at home. A single mother wrote, "It is very hard to do this as a single parent, who works all the 
time. We have our own form of communication. He gestures a lot, and it makes it so much harder to be a good parent. I don't know the solution, but if there is one let me know."

Additionally, families identified a desire for additional social networks and parent support groups. Fourteen respondents expressed a desire for additional parent support groups. One participant stated, "Parents need to be able to meet and talk with parents and families of deaf kids." Another participant wrote, "A support group of families with children of all ages who have hearing loss would be very helpful."

Other comments were directed toward the lack of community inclusion. Parents noted the lack of community awareness and education regarding the unique needs of children who are hard of hearing or deaf. The comments mentioned the need to provide resources and training for individuals leading activities in the community such as Sunday school and child care. Community child care was also mentioned by more than one family as an area of inadequate knowledge and resources in the community. Participants identified the need for resources and training for child care providers to accommodate the special needs of all of their family members. One family member wrote that parents needed "child care options with caregivers who are comfortable with hearing aids or cochlear implants_-or some resources to help find these types of caregivers." Similarly, another parent wrote, "Daycare for my son has been hard. One place never put the hearing aids in. The second place did, but then stopped. Perhaps there could be a program for child care providers who take these kids and do what needs to be done."

\section{DISCUSSION}

The purpose of this study was to investigate families' perception of quality of life and their satisfaction with their child's communication outcomes in order to assist service providers in implementing family-centered supports following the early identification of hearing loss. This study investigated and described families' satisfaction with outcomes and the impact of deafness on family life for families with young children who received early intervention. Responses from 207 returned surveys were analyzed to examine these outcomes. This section will summarize the results, discuss the findings and limitations, and suggest implications for family centered-practices.

\section{Impact and Satisfaction With Family Life}

Families in this study reported being generally satisfied with all areas of family life. Based on the resiliency model of family stress, relatively high satisfaction with family life may suggest that families are receiving supports that mediate the stressors or demands related to deafness. Relatively high satisfaction with early intervention is consistent with findings of other recent studies (Lederberg \& Golbach, 2002; Neuss, 2006; Young \& Tattersall, 2007; Zaidman-Zait, 2007). Of the 23 mothers in the Lederberg and Golbach (2002) study, 70\% reported fairly good to very good life satisfaction (4 or 5 on a 5-point scale). Nearly all of the parents in three qualitative inquiries expressed positive feedback and high satisfaction with the early intervention services they received (Neuss, 2006; Young \& Tattersall, 2007; Zaidman-Zait, 2007).

Variables that contribute to the perception of satisfaction cannot be determined completely from this study. General satisfaction may reflect positively on the experiences and outcomes of families during early intervention. Frustrations and negative experiences commonly reported in the literature with a late diagnosis may have been attenuated or prevented by early identification and early intervention. The fact that families were generally satisfied may be an indicator that early intervention supports were effectively mediating the demands on the family. However, the perception of satisfaction may be related more to the fact that the families in this study received early identification and early intervention services rather than a reflection of the quality of those services.

Although the general ratings of satisfaction in this study were high, it cannot be inferred that family needs were adequately mediated by early intervention. Satisfaction may be difficult to interpret, as the relative meaning of being satisfied is an individual perception. Family appraisal may be heavily influenced by expectation, making it possible for one family to report high satisfaction with experiences and outcomes while another family reports being less satisfied with the same experiences and outcomes. Some families may set the bar quite high, whereas others may be satisfied with much less. Another possible contributor to the high incidence of positive comments is the age of the children in this study. Other studies have reported that families of young children report higher ratings of satisfaction with services and outcomes than do families of older children (McWilliam et al., 1995).

Despite generally positive perceptions of family life, the families in our study noted high impact and lower satisfaction in the areas of emotional well-being, time demands, financial well-being, and support for the child who is deaf. Specific items with lower observed satisfaction included having time to pursue individual interests, having support to relieve stress, getting support from local agencies, having support for the child to be included in the community, and having a way to take care of expenses. Numeric ratings on the survey for these items were only slightly lower than for other items; however, their importance to families was supported by the participants' written comments. Based on the model of family stress, this finding may be interpreted as an imbalance between demands and resources. When the severity of stressors exceeds the resiliency resources of the family, the members are unable to adapt positively.

Emotional well-being. The trend in lower satisfaction with emotional well-being on the scale is consistent with the written comments of family members, which provide insight into aspects that may have contributed to lower perceptions of emotional satisfaction. In the current study, families highlighted the need for support for emotional well-being, stress relief, counseling, and time to pursue interests. These findings substantiate the importance of emotional support, which has also been emphasized in related research (Burger et al., 2005; Hintermair, 2006; Lederberg \& Golbach, 2002; Most \& Zaidman-Zait, 2003; Neuss, 2006).

Heightened stress and diminished emotional well-being have not consistently been evidenced in the literature. Other studies have reported normal stress levels (Meadow-Orlans et al., 2004; Weisel et al., 2007) or noted differences in emotional well-being across time (Burger et al., 2005; Lederberg \& Golbach, 2002; Neuss, 2006). It is speculated that these discrepancies in ratings of emotional wellbeing may be the result of differences in one or more factors, including the measurement tools used, availability and quality of support services, amount of socioemotional support, communication skills, and availability of financial and informational resources.

In the current study, there appeared to be similarities between participants' perceptions of satisfaction and the degree of impact of deafness for emotional well-being. Items on the scale most impacted by deafness were also ranked as areas of lower satisfaction; although 
causality cannot be inferred from the data. The areas that participants ranked as being most strongly impacted by deafness (time and stress) were some of the same areas about which families reported being least satisfied (time to pursue individual interests and having ways to relieve stress). These trends in satisfaction and the impact of deafness related to stress and increased time demands coincide with relationships that have been suggested previously in the literature (Calderon et al., 1998; Evans, 1995; Quittner et al., 1991). Feelings of stress and time demands may also be complicated by the time and efforts required for learning new communication skills and strategies (Evans, 1995; Freeman et al., 2002; Henderson \& Hendershott, 1991). Causality cannot be inferred or implied from the results of the current study. Participants were asked to appraise their family quality of life, but the questionnaire was not designed to determine causality. Recognizing the dynamic nature of the family system, it is more likely that multiple stressors contributed to families' appraisal of lower satisfaction with emotional well-being.

Social supports. Perceptions of somewhat lower satisfaction with emotional well-being may be related to the need for social connections and networks. The importance of parent support groups and the need for social networks with other parents was a reoccurring theme in the comments of family members in the current study. This is consistent with comments of families in recent qualitative studies (Jackson et al., 2008; Neuss, 2006; Zaidman-Zait, 2007) noting the importance of meeting other individuals with similar experiences. This finding also coincides with Lederberg and Golbach (2002), who substantiated a relationship between ratings of social support, parenting stress, and life satisfaction for 23 parents of 3-year-old children who were deaf.

Access to support from local agencies. Possible explanations for lower satisfaction scores in accessing support from local agencies include limited availability of preferred options, educational supports, and service providers with specialized training. The importance of a variety of informational supports has been underscored in several recent studies (Most \& Zaidman-Zait, 2003; Ross \& Lyon, 2007; Zaidman-Zait, 2007). In Most and Zaidman-Zait (2003), 22.7\% of the parents surveyed reported that they lacked information on communication, and $36.4 \%$ reported that they lacked technical information. Low satisfaction with accessibility of supports may also be influenced by distance. Geographic barriers may negatively affect parents' access to desired supports and service providers with specialized training. Furthermore, in the written comments, families expressed the need to increase their access to options in educational programming and supports for community inclusion. Desired educational programs and supports included transition from Part $\mathrm{C}$ to Part B services; access to oral and auditory verbal programs, interpreters, and deaf mentors and role models; and improved preschool and child care options.

\section{Satisfaction With Child Outcomes in Communication Skills}

As expected, families reported deafness to have a large impact on their child's communication outcomes. Results also indicated that families in this study were generally satisfied with their child's progress in speech, language, and listening. This may be due in part to the fact that children in this study were largely identified early and received early intervention. Other studies have observed positive effects of early identification on communication achievement (Yoshinaga-Itano, Sedey, Coulter, \& Mehl, 1998). Yoshinaga-Itano et al. (1998) found that children who were identified at birth and fitted with amplification by
6 months showed accelerated communication development compared to children who were identified after 18 months of age.

However, there were significant differences in perceptions between participant groups for satisfaction with child outcomes. For example, family members of children using cochlear implants and the oral communication method were more satisfied with their children's progress in clarity of speech and speech perception than were family members of children using hearing aids alone and sign language. These findings substantiate previous reports that the use of cochlear implants at an early age with an oral communication method is associated with higher satisfaction with speech production and perception. This finding coincides with Nikolopoulos, Lloyd, Mphil, and O'Donoghue (2001), in which 98\% of parents indicated that their child's outcomes after cochlear implantation met or surpassed their expectations. There is a large body of literature documenting improvements in speech perception, speech production, and general language skills following cochlear implantation (Bohnert, Spitzlei, Lippert, \& Keilmann, 2007; Kirk, Miyamoto, Ying, Perdew, \& Zuganellis, 2003; Ross \& Lyon, 2007; Sharma, Dorman, Spah, \& Todd, 2002; Zwolan et al., 2004).

The reported differences in satisfaction with child outcomes should be interpreted cautiously. The items on the questionnaire used to survey satisfaction with child outcomes were supplemental questions that were not included in the original field-tested FQoL scale. Due to the limitations of survey methodology, it cannot be inferred that all respondents shared the same conceptualization as professionals in their understanding of the terms speech production, language use, and speech perception. Additionally, the groups of participants using each type of sensory device were not equally distributed by communication method or income and educational level. A higher percentage of children reportedly used oral communication following implantation. Furthermore, the covariance of communication mode and sensory device on higher satisfaction with outcomes cannot be splintered out in the current findings.

\section{Limitations}

The findings may not adequately reflect the perceptions of multiple members of the family or families from culturally and linguistically diverse backgrounds. Respondents consisted primarily of mothers; therefore, it cannot be assumed that fathers or other family members would respond similarly. Furthermore, the demographics of the sample did not reflect a cross-section of the national population in terms of racial/ethnic background, education level, and income. A larger proportion of participants were European American, middle income, and had postsecondary education compared to the demographic distribution of the national population. In particular, Hispanic and African American populations were underrepresented in the sample. This underrepresentation is consistent with other reports that families from culturally and linguistically diverse backgrounds and families with lower levels of formal education are less likely to participate in mail surveys (Dillman, 2000).

\section{Clinical Implications and Recommendations}

Despite the study's limitations, the perceptions and experiences of the respondents offer clinical implications for family-centered service provision, program evaluation, and future research efforts.

Implications for family-centered service provision. Interpretation of the current findings in light of the resiliency model of family 
stress supports the need for family-centered early invention to focus on the balance between resilience resources and demands on the family system. Families may benefit from services that strive to build the capacity or resilience of families by tailoring support to the various domains of family life. Based on the descriptive findings of this study, it is recommended that programs infuse additional service supports, especially related to addressing emotional needs, reducing time demands, and accessing financial assistance.

Emotional supports. Based on the written comments of families, socioemotional supports are important buffers that mediate the impact of stressors on family quality of life. Families of children who are deaf may benefit from family support services that address the emotional needs of each member. Family resilience may be enhanced by informational resources and service options that are responsive to the individual needs and preferences of family members. Family support organizations and local parent support groups may be beneficial in providing role models, mentoring, and social support. Social networks and resources have been observed to support coping, coherence, and adjustment of parents (Calderon \& Greenberg, 1999; Hintermair, 2006; Lederberg \& Golbach, 2002).

Reducing time demands. To be responsive to families' perceived need for more time to meet the demands of all family members, service providers may consider increasing sensitivity to the skills and time required to implement interventions in the home. Alternative service delivery options may need to be explored. Regular respite care may also be considered to help relieve families' feelings of stress and time demands.

Financial assistance. Families of children who are deaf may benefit from additional information and support to access financial assistance for assistive listening devices, services, and other needs. Options for funding hearing aids, batteries, and specialized services need to be clearly explained. Additional support may be available through insurance benefits, government benefits, and assistance from local philanthropic organizations; but families may need assistance in locating and accessing available resources.

Suggestions for future research. These results suggest that family members are generally satisfied with preliminary services and outcomes during early intervention. Additional follow-up studies are recommended to observe the perceptions of family members at different age levels and developmental stages. The use of a family quality of life questionnaire or similar scale may be beneficial for programs and agencies to identify program-level strengths and needs. Additional research is also warranted to identify variables that contribute to family satisfaction with child and family outcomes to enhance overall family quality of life.

\section{ACKNOWLEDGMENTS}

We would like to thank the families for sharing their insights and experiences with us. Sincere thanks are also extended to Debora Daniels, Sally Roberts, and Diane Frome Loeb, who provided feedback on an earlier version of the manuscript.

\section{REFERENCES}

Abidin, R. R. (1990). Parenting Stress Index (PSI) manual (3rd ed.). Charlottesville, VA: Pediatric Psychology Press.
Allen, R. I., \& Petr, C. G. (1996). Toward developing standards and measurements for family-centered practice in family support programs. In G. H. S. Singer, L. E. Powers, \& A. L. Olson (Eds.), Redefining family support: Innovations in public-private partnerships (pp. 57-86). Baltimore, MD: Brookes.

Bailey, D. B., \& Bruder, M. B. (2005). Family outcomes of early intervention and early childhood special education: Issues and considerations. Menlo Park, CA: Early Childhood Outcomes Center.

Bailey, D. B., McWilliam, R. A., Darkes, L. A., Hebbeler, K., Simeonsson, R. J., Spiker, D., \& Wagner, M. (1998). Family outcomes in early intervention: A framework for program evaluation and efficacy research. Exceptional Children, 64(3), 313-328.

Bodner-Johnson, B. (1986). The family environment and achievement of deaf students: A discriminant analysis. Exceptional Children, 52(5), 443-449.

Bodner-Johnson, B. (1991). Family conversational style: Its effect on the deaf child's participation. Exceptional Child, 57(6), 502-509.

Bohnert, A., Spitzlei, V., Lippert, K., \& Keilmann, A. (2007). Bilateral cochlear implantation in children: Experiences and considerations. Volta Review, 106(3), 343-364.

Brown, R., Davey, R., Shearer, J., \& Kyrkou, M. (2004). Family quality of life in Australia. In A. P. Turnbull, I. Brown, \& H. R. Turnbull (Eds.), Families and people with mental retardation and quality of life: International perspectives (pp. 221-260). Washington, DC: American Association on Mental Retardation.

Bruder, M. (2000). Family-centered early intervention: Clarifying our values for the new millennium. Topics in Early Childhood Special Education, 20(2), 105-115.

Bullinger, M., Kirchberger, I., \& Steinbuchel, N. (1993). The Everyday Life Questionnaire: An instrument for the assessment of health-related quality of life. Zeitschrift fur Medizinische Psychologie, 3, 121-131.

Burger, T., Spahn, C., Richter, B., Eissele, S., Erwin, L., \& Bengel, J. (2005). Parental distress: The initial phase of hearing aid and cochlear implant fitting. American Annals of the Deaf, 150(1), 5-10.

Calderon, R., Bargones, J., \& Sidman, S. (1998). Characteristics of hearing families and their young deaf and hard of hearing children: Early intervention follow-up. American Annals of the Deaf, 143(4), 347-362.

Calderon, R., \& Greenberg, M. (1999). Stress and coping in hearing mothers of children with hearing loss: Factors affecting mother and child adjustment. American Annals of the Deaf, 144(1), 7-18.

Church, A. H. (1993). Estimating the effect of incentives on mail survey response rates. A meta-analysis. Public Opinion Quarterly, 57, $62-79$.

Cummins, R. A. (1997). Assessing quality of life. In R. I. Brown (Ed.), Assessing quality of life for people with disabilities: Models, research and practice (pp. 116-150). Cheltenham, UK: Stanley Thornes.

Dillman, D. (2000). Mail and Internet surveys: The tailored design method (2nd ed.). New York, NY: John Wiley \& Sons.

Dunst, C. (2002). Family-centered practices: Birth through high school. The Journal of Special Education, 36(3), 139-147.

Evans, J. (1995). Conversation at home: A case study of a young deaf child's experiences in a family in which all others can hear. American Annals of the Deaf, 140(4), 324-332.

Freeman, B., Dieterich, C., \& Rak, C. (2002). The struggle for language: Perspectives and practices of urban parents with children who are deaf or hard of hearing. American Annals of the Deaf, 147(5), 37-44.

Gregory, S., Bishop, J., \& Shelton, L. (1995). Deaf young people and their families: Developing understanding. New York, NY: Cambridge University Press.

Guralnick, M. (1997). The effectiveness of early intervention: Directions for second generation research. Baltimore, MD: Brookes. 
Henderson, D., \& Hendershott, A. (1991). ASL and the family system. American Annals of the Deaf, 136(4), 325-329.

Hill, R. (1949). Families under stress. New York, NY: Harper \& Row.

Hill, R. (1958). Generic features of families under stress. Social Casework, 49, 139-150.

Hintermair, M. (2000). Hearing impairment, social networks, and coping: The need for families with hearing-impaired children to relate to other parents and to hearing-impaired adults. American Annals of the Deaf, 145(1), 41-53.

Hintermair, M. (2006). Parental resources, parental stress, and socioemotional development of deaf and hard of hearing children. Journal of Deaf Studies and Deaf Education, 11(4), 493-507.

Hughes, C., \& Hwang, B. (1996). Attempts to conceptualize and measure quality of life. In R. L. Schalock (Ed.), Quality of life: Vol. 1. Conceptualization and measurement (pp. 51-61). Washington, DC: American Association on Mental Retardation.

Individuals With Disabilities Education Act Amendments of 1997, P. L. 105-17, 20 U.S.C. $\$ 1400$ et seq. (1997).

Jackson, C. W., Traub, R. J., \& Turnbull, A. P. (2008). Parents' experiences with childhood deafness: Implications for family-centered services. Communication Disorders Quarterly, 29, 82-98.

Jackson, C. W., \& Turnbull, A. P. (2004). The impact of deafness on family life: A review of the literature. Topics in Early Childhood Special Education, 24(1), 15-29.

Kashyap, L. (1986). The family's adjustment to their hearing impaired child. Indian Journal of Social Work, 47(1), 31-37.

Kirk, K., Miyamoto, R., Ying, E., Perdew, A., \& Zuganellis, H. (2003). Cochlear implantation in young children: Effects of age of implantation and communication mode. Volta Review, 102(4), 127-144.

Lederberg, A., \& Golbach, T. (2002). Parenting stress and social support in hearing mothers of deaf and hearing children: A longitudinal study. Journal of Deaf Studies and Deaf Education, 7(4), 330-345.

McCubbin, M. A., \& McCubbin, H. I. (1993). Families coping with illness: The resiliency model of family stress, adjustment, and adaptation. In C. B. Danielson, B. Hamel-Bissell, \& P. Winstead-Fry (Eds.), Families, health, \& illness: Perspectives on coping and intervention (pp. 21-61). St. Louis, MO: Mosby.

McCubbin, M. A., \& Patterson, J. M. (1983). The family stress process: The double ABCX model of adjustment and adaptation. In H. McCubbin, M. Sussman, \& J. Patterson (Eds.), Advances and developments in family stress theory and research (pp. 7-37). New York, NY: Haworth.

McWilliam, R. A., Lang, L., Vandiviere, P., Angell, R., Collins, L., \& Underdown, G. (1995). Satisfaction and struggles: Family perceptions of early intervention services. Journal of Early Intervention, 19(1), 43-60.

Meadow-Orlans, K. P., Mertens, D., Sass-Lehrer, M., \& Scott-Olson, K. (1997). Support services for parents and their children who are deaf or hard of hearing: A national study. American Annals of the Deaf, 142, 278-293.

Meadow-Orlans, K. P., Spencer, P. E., \& Koester, L. S. (2004). The world of deaf infants: A longitudinal study. New York, NY: Oxford University Press.

Moores, D., Jatho, J., \& Dunn, C. (2001). Families with deaf members: American Annals of the Deaf, 1996-2000. American Annals of the Deaf, 146(3), 245-250.

Most, T., \& Zaidman-Zait, A. (2003). The needs of parents of children with cochlear implants. Volta Review, 103(2), 99-113.

Neuss, D. (2006). The ecological transition to auditory-verbal therapy: Experiences of parents whose children use cochlear implants. Volta Review, 106(2), 195-222.
Nikolopoulos, T., Lloyd, H., Mphil, S., \& O'Donoghue, G. (2001). Pediatric cochlear implantation: The parent's perspective. Archives of Otolaryngology-Head \& Neck Surgery, 127, 363-367.

Park, J., Hoffman, L., Marquis, J., Turnbull, A. P., Poston, D., \& Mannan, H. (2003). Toward assessing family outcomes of service delivery: Validation of a family quality of life survey. Journal of Intellectual Disability Research, 47(4/5), 367-384.

Poston, D., Turnbull, A. P., Park, J., Mannan, H., Marquis, J., \& Wang, M. (2003). Family quality of life outcomes: A qualitative inquiry launching a long-term research program. Mental Retardation, 41(5), 313-328.

Quittner, A. L., Steck, J. T., \& Rouiller, R. L. (1991). Cochlear implants in children: A study of parental stress and adjustment. American Journal of Otology, 12(Supp.), 95-104.

Ross, L., \& Lyon, P. (2007). Escaping a silent world: Profound hearing loss, cochlear implants and household interaction. International Journal of Consumer Studies, 31, 357-362.

Sharma, A., Dorman, M., Spah, A., \& Todd, N. (2002). Early cochlear implantation in children allows normal development of central auditory pathways. Annals of Otology, Rhinology \& Laryngology, 189(Suppl.), $38-41$.

Summers, J. A., Poston, D. J., Turnbull, A. P., Marquis, J., Hoffman, L., Mannan, H., \& Wang, M. (2005). Conceptualizing and measuring family quality of life. Journal of Intellectual Disability Research, 49(10), $777-783$.

Turnbull, A. P., \& Turnbull, H. R. (2001). Families, professionals, and exceptionality: Collaborating for empowerment (4th ed). Upper Saddle River, NJ: Merrill/Prentice Hall.

Turnbull, H. R., Turnbull, A. P., Wehmeyer, M., \& Park, J. (2003). A quality of life framework for special education outcomes. Remedial and Special Education, 24(2), 67-74.

Weisel, A., Most, T., \& Michael, R. (2007). Family characteristics since child's implantation. Journal of Deaf Studies and Deaf Education, 12(1), $55-64$.

Yoshinaga-Itano, C., Sedey, A., Coulter, D. K., \& Mehl, A. L. (1998). Language of early and later identified children with hearing loss. Pediatrics, 102, 1161-1171.

Young, A., \& Tattersall, H. (2007). Universal newborn hearing screening and early identification of deafness: Parents' responses to knowing early and their expectations of child communication development. Journal of Deaf Studies and Deaf Education, 12(2), 209-220.

Zaidman-Zait, A. (2007). Parenting a child with a cochlear implant: A critical incident study. Journal of Deaf Studies and Deaf Education, 12(2), 221-241.

Zwolan, T., Ashbaugh, C., Alarfaj, A., Kileny, P., Arts, H., El-Kashlan, H., \& Telian, S. (2004). Pediatric cochlear implant patient performance as a function of age at implantation. Otology \& Neurotology, 25, 112-120.

Received December 31, 2007

Accepted December 23, 2008

DOI: $10.1044 / 0161-1461(2009 / 07-0093)$

Contact author: Carla Wood Jackson, Florida State University, Communication Disorders, 109 Regional Rehabilitation Center, Tallahassee, FL 32309. E-mail: cjackson3@fsu.edu. 